\title{
Diffusion Coatings for Corrosion-Resistant Components in Coal Gasification Systems
}

Quarterly Technical Progress Report 15

Covering the period January 1, 2007 through March 31, 2007

SRI Project P13063

Contract No.: DE-FC26-03NT41616

Prepared by:

Gopala N. Krishnan, Ripudaman Malhotra, Esperanza Alvarez, Kai-Hung Lau, Jordi Perez-Mariano, and Angel Sanjurjo

SRI International

333 Ravenswood Avenue

Menlo Park, CA 94025

Prepared for:

U.S. Department of Energy

National Energy Technology Center

P. O. Box 10940

Pittsburgh, PA 15236

Attention: Dr. Richard Read 


\section{DISCLAIMER}

This report was prepared as an account of work sponsored by an agency of the United States Government. Neither the United States Government nor any agency thereof, nor any of their employees, makes any warranty, express or implied, or assumes any legal liability or responsibility for the accuracy, completeness, or usefulness of any information, apparatus, product, or process disclosed, or represents that its use would not infringe privately owned rights. Reference herein to any specific commercial product, process, or service by trade name, trademark, manufacturer, or otherwise does not necessarily constitute or imply endorsement, recommendation, or favoring by the United States Government or any agency thereof. The views and opinions of authors expressed herein do not necessarily state or reflect those of the United States Government or any agency thereof. 


\begin{abstract}
Heat-exchangers, particle filters, turbines, and other components in integrated coal gasification combined cycle system must withstand the highly sulfiding conditions of the hightemperature coal gas over an extended period of time. The performance of components degrades significantly with time unless expensive high alloy materials are used. Deposition of a suitable coating on a low-cost alloy may improve its resistance to such sulfidation attack, and decrease capital and operating costs. The alloys used in the gasifier service include austenitic and ferritic stainless steels, nickel-chromium-iron alloys, and expensive nickel-cobalt alloys.

During this period, we analyzed several 409 low alloy steel samples after coating them in our fluidized bed reactor and also after exposing them to our corrosion test. We report the following findings:
\end{abstract}

1. A protective coating was deposited inside a porous 409 steel sample to protect it from sulfidation attack. The coating was based on a combination of $\mathrm{Si}$ diffusion layer, $\mathrm{Nb}$ interlayer and nitrides of titanium and silicon.

2. Analysis of solid coupons exposed to simulated coal gas at $900^{\circ} \mathrm{C}$ for $300 \mathrm{~h}$ showed that multilayer metal/ceramic coatings provide a better protection than ceramic coatings.

3. Deposition of several ceramic/metal multilayer coatings showed that coatings with niobium and tantalum interlayers have good adhesion. However, coatings with a tungsten interlayer suffered localized delaminating and coatings with $\mathrm{Zr}$ interlayers showed poor adhesion.

4. Analysis of solid coupons, coated with the above-mentioned multilayer films, after exposure to simulated coal gas at $900^{\circ} \mathrm{C}$ for $300 \mathrm{~h}$ showed that niobium is the best candidate for interlayer material. 


\section{TABLE OF CONTENTS}

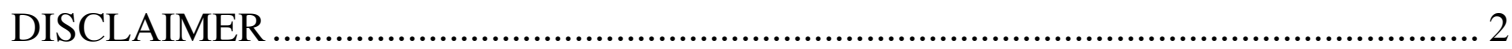

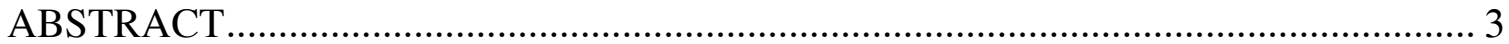

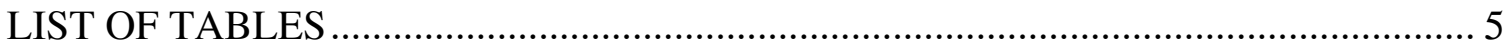

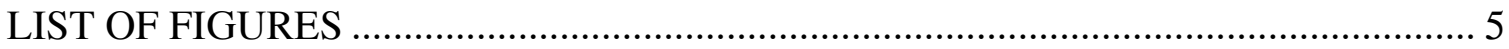

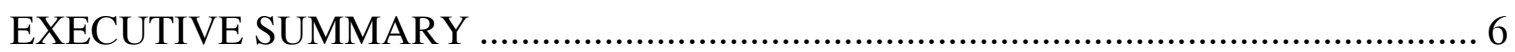

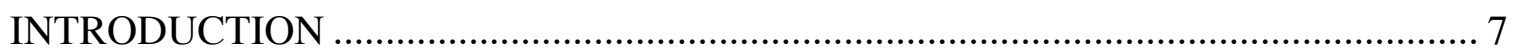

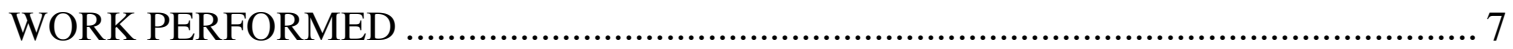

Analysis of a porous coupon exposed to simulated coal gas ..................................8

Analysis of coated steel plates exposed to simulated coal gas .................................9

Analysis of coupons exposed to simulated coal gas .............................................15

Analyses of multilayer-coated coupons after exposure to coal gas .........................17

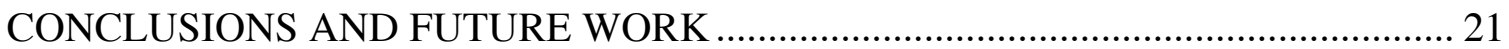




\section{LIST OF TABLES}

1. Deposition conditions (coating composition and deposition time), weight gain during both the coating process and the corrosion test ................................................................

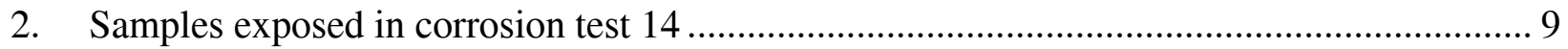

3. EDX results, iron sulfide crystals on several samples ................................................. 11

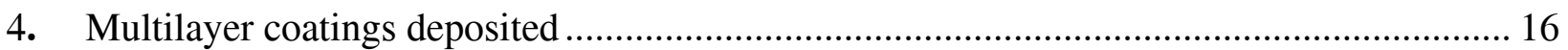

\section{LIST OF FIGURES}

1. SEM cross-section of a fractured sample from Run 109 after exposure to simulated coal gas at $370^{\circ} \mathrm{C}$ for $300 \mathrm{~h}$.

2. Samples before and after exposure for $300 \mathrm{~h}$ at $900^{\circ} \mathrm{C}$ in simulated gasifier Test $14 \ldots . \quad 10$

3. X-ray diffraction pattern of the crystals that grew around the orifice of the sample from Run 95 during exposure to simulated coal gas at $900^{\circ} \mathrm{C}$ for $300 \mathrm{~h}$

4. SEM top views at different magnifications of the zone that survived the corrosion test (scale bars are $200 \mu \mathrm{m}$ in the top micrograph and $3 \mu \mathrm{m}$ in the bottom micrograph).............. 12

5. EDX spectrum acquired in the zone showed in Figure 4 (left-hand micrograph)......... 13

6. X-ray diffraction pattern of the zone from coupon 112 that survived sulfidation during

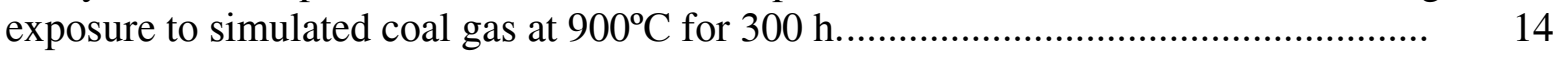

7. Cross-section micrograph of the exposed coupon from Run 112 after fracturing........ 15

8. SEM cross-section of a sample from Run 120 showing the substrate (bottom), the multilayer coating and the mounting polymer (top) ............................................................. 16

9. SEM cross-section of the fractured sample showing a closer view of the coating. ....... 17

10. Samples before and after exposure for $300 \mathrm{~h}$ at $900^{\circ} \mathrm{C}$ in simulated gasifier Test $15 \ldots . \quad 18$

11. SEM top view of the coupon from Run 119 after exposure to simulated coal gas at $900^{\circ} \mathrm{C}$ for $300 \mathrm{~h}$ (scale is $10 \mu \mathrm{m})$

12. X-ray diffraction pattern, coupon from Run 119 after exposure to simulated coal gas at $900^{\circ} \mathrm{C}$ for $300 \mathrm{~h}$.

13. Cross-section micrographs at two different magnifications of the exposed coupon from Run 119 after fracturing.

14. Elemental EDX line analysis across the coating shown in the bottom micrograph in Figure 13 (Origin in $\mathrm{x}$-axis corresponds to coating surface). 


\section{EXECUTIVE SUMMARY}

Advanced coal gasification systems such as integrated coal gasification combined cycle (IGCC) processes offer many advantages over conventional pulverized coal combustors. Heatexchangers, filters, turbines, and other components in IGCC plants often must withstand the highly sulfiding conditions at high temperatures. In collaboration with U.S. Department of Energy and ConocoPhillips, we are developing corrosion-resistant coatings for high-temperature components in IGCC systems.

SG Solution's coal gasification power plant in Terre Haute, IN, uses ConocoPhillips' E-Gas technology. The need for corrosion-resistant coatings exists in two areas: (1) the tube sheet of a heat exchanger at $\sim 1000^{\circ} \mathrm{C}$ that is immediately downstream of the gasifier, and (2) porous metal particulate filter at $370^{\circ} \mathrm{C}$, which is downstream of the heat exchanger. These components operate at gas streams containing as much as $2 \% \mathrm{H}_{2} \mathrm{~S}$. A protective metal or ceramic coating that can resist sulfidation corrosion will extend the life-time of these components and reduce maintenance.

During this period, we analyzed several 409 low alloy steel samples after coating them in

our fluidized bed reactor and also after exposing them to our corrosion test. We report the following findings:

1. A protective coating was deposited inside a porous 409 steel sample to protect it from sulfidation attack. The coating was based on a combination of $\mathrm{Si}$ diffusion layer, $\mathrm{Nb}$ interlayer and nitrides of titanium and silicon.

2. Analysis of solid coupons exposed to simulated coal gas at $900^{\circ} \mathrm{C}$ for $300 \mathrm{~h}$ showed that multilayer metal/ceramic coatings provide a better protection than ceramic coatings.

3. Deposition of several ceramic/metal multilayer coatings showed that coatings with niobium and tantalum interlayers have good adhesion. However, coatings with a tungsten interlayer suffered localized delaminating and coatings with $\mathrm{Zr}$ interlayers showed poor adhesion.

4. Analysis of solid coupons, coated with the above-mentioned multilayer films, after exposure to simulated coal gas at $900^{\circ} \mathrm{C}$ for $300 \mathrm{~h}$ showed that niobium is the best candidate for interlayer material. 


\section{INTRODUCTION}

Heat-exchangers, filters, turbines, and other components in coal-fired power plants must withstand demanding conditions of high temperatures and pressure differentials. Further, the components are exposed to corrosive gases and particulates that can erode the material and degrade their performance. In collaboration with U.S. Department of Energy and ConocoPhillips, SRI International recently embarked on a project to develop corrosionresistant coatings for coal-fired power plant applications. Specifically, we are seeking to develop coatings that would prevent the corrosion in the tube-sheet of the high-temperature heat recovery unit of a coal gasification power plant of SG Solution's plant in Terre Haute, IN, which uses ConocoPhillips' E-Gas technology. This corrosion is the leading cause of the unscheduled downtime at the plant and hence success in this project will directly impact the plant availability and its operating costs. Coatings that are successfully developed for this application will find use in similar situation in other coal-fired power plants.

\section{WORK PERFORMED}

Previously, we showed that the coatings of nitrides of $\mathrm{Ti}, \mathrm{Al}$, and $\mathrm{Si}$ can provide alloy steels significant resistance to sulfidation attack in simulated coal gas streams. In bench scale tests, the coated 409 plates showed significant resistance to a $\mathrm{H}_{2} \mathrm{~S}(2 \% \mathrm{v} / \mathrm{v})$ containing gas stream at $370^{\circ} \mathrm{C}$ while sulfidation attack occurred at $900^{\circ} \mathrm{C}$. We showed that the challenge in porous substrates is to deposit these protective coatings in the bulk of the coupons. During this quarter, we finished the study of porous substrates adjusting deposition conditions to protect the bulk of the sample. We analyzed solid coupons after a high-temperature corrosion test and found that interlayers of metals such as $\mathrm{Nb}$ or $\mathrm{W}$ increase resistance to sulfidation attack in simulated coal stream gas. 


\section{ANALYSIS OF A POROUS COUPON EXPOSED TO SIMULATED COAL GAS}

This corrosion test completes the study of porous coupons discussed in our previous quarterly report. We reported that titanium-based nitride coatings with a $\mathrm{Nb}$ diffusion barrier increased the sulfidation resistance of porous coatings, but still needed some improvement in the bulk of the samples. During this quarter we adjusted deposition conditions (Run 109 in Table 2, compared with previously reported Runs). As seen in Table 2, we found the highest weight gain during deposition in Run 109, indicating an overall thicker coating was deposited. This observation correlates with the lower weight gain measured during the corrosion test, which indicates the lowest sulfidation degree of all exposed porous coupons.

Table 1. Deposition conditions (coating composition and deposition time), weight gain during both the coating process and the corrosion test.

\begin{tabular}{|c|c|c|c|c|c|}
\hline Run & $\begin{array}{c}\text { Diffusion } \\
\text { Layer }\end{array}$ & $\begin{array}{c}\text { Barrier } \\
\text { Layer }\end{array}$ & $\begin{array}{c}\text { Ceramic } \\
\text { Film }\end{array}$ & $\begin{array}{c}\text { Weight Gain \% } \\
\text { (coating) }\end{array}$ & $\begin{array}{c}\text { Weight Gain \% } \\
\text { (corrosion test) }\end{array}$ \\
\hline 93 & TiAl (6h) & - & TiAISiN (7h) & 2.4 & 10.3 \\
\hline 102 & TiAISi (6h) & - & TiAISiN (2.5h) & 3.1 & 5.1 \\
\hline 104 & TiAl (8h) & $\mathrm{Nb}$ & TiAIN (4h) & 3.5 & 7.9 \\
\hline 109 & TiSi (10h) & $\mathrm{Nb}$ & TiSiN (6h) & 6.7 & 3.1 \\
\hline
\end{tabular}

However, the weight gain of $3 \%$ during the corrosion test of Run 109 coupons indicates that some sulfidation has taken place. To investigate this, we fractured the exposed sample and observed it under a scanning electron microscope (SEM). As shown in Figure 1, the sample suffered sulfidation only on one side, close to the surface. Since the gas feeding systems in our lab reactor are not optimized, it happens occasionally that one side of a coupon is less exposed to the reactants than the other. However, the most important observation in Figure 1 is that the bulk of the sample was not attacked during the corrosion test. The porous structure of the filter remained unplugged and, most important, we did not find any sulfur by energy dispersive X-ray analysis (EDX) measurements. These results show that with optimization of the deposition conditions protective coatings can be deposited even in the bulk of the samples. 


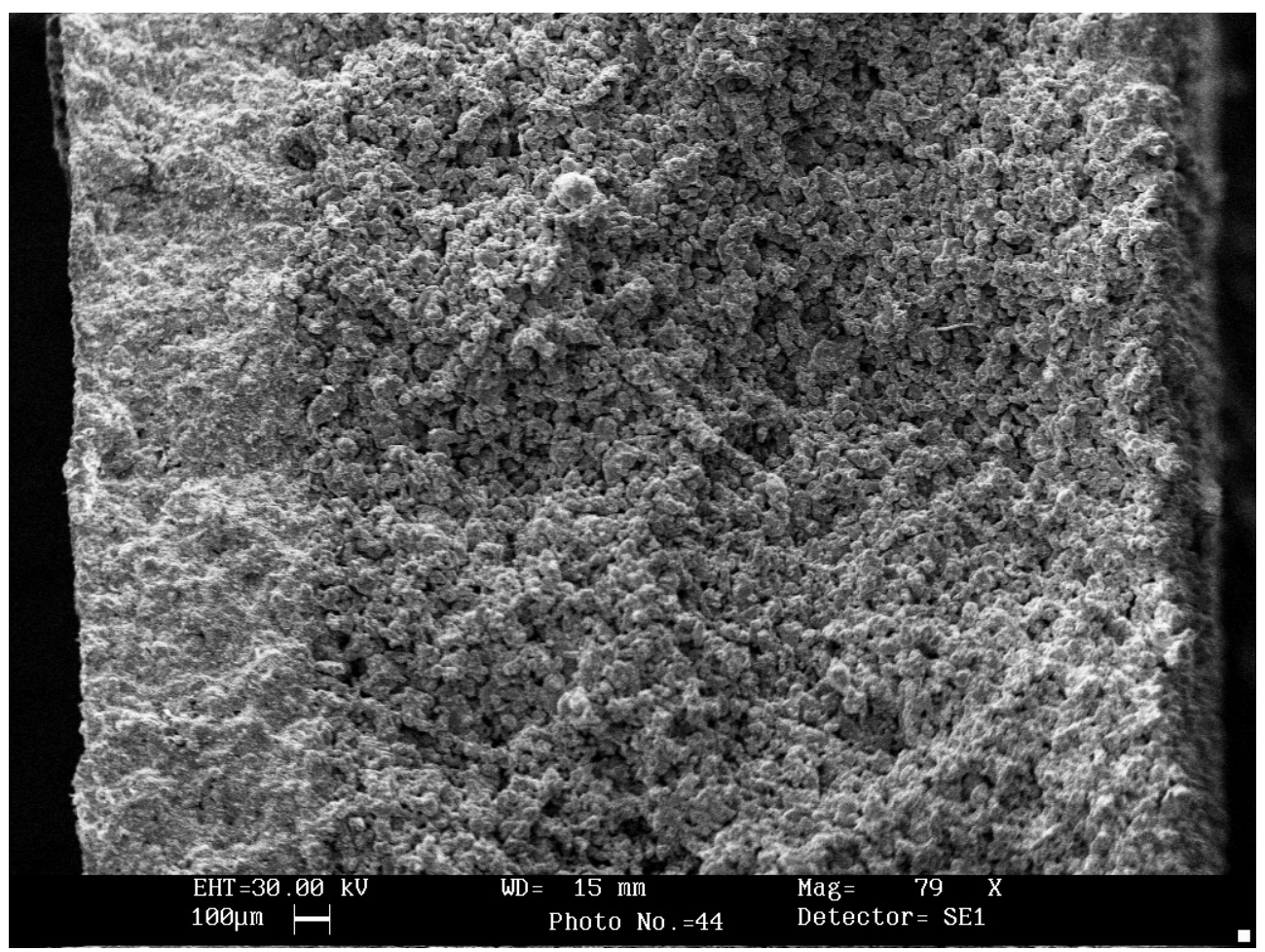

Figure 1. SEM cross-section of a fractured sample from Run 109 after exposure to simulated coal gas at $370^{\circ} \mathrm{C}$ for $300 \mathrm{~h}$.

\section{ANALYSIS OF COATED STEEL PLATES EXPOSED TO SIMULATED COAL GAS}

The top panel of Figure 2 shows the picture of the samples before they were exposed to simulated gasifier conditions at $900^{\circ} \mathrm{C}$. The bottom panel is a photograph of the samples after exposure after $300 \mathrm{~h}$. Table 2 lists the samples and the specific coatings.

Table 2. Samples exposed in corrosion test 14.

\begin{tabular}{|c|c|c|}
\hline Run & Material & Coating \\
\hline 94 & SS409 & $(\mathrm{Ti}, \mathrm{Si}) \mathrm{N} /(\mathrm{Ti}, \mathrm{Al}) \mathrm{N} / \mathrm{TiAl}$ \\
\hline 95 & $\mathrm{SS} 409$ & $(\mathrm{Ti}, \mathrm{Si}) \mathrm{N} / \mathrm{W} /(\mathrm{Ti}, \mathrm{Si}) \mathrm{N} / \mathrm{W} / \mathrm{TiAl}$ \\
\hline 98 & SS409 & $(\mathrm{Ti}, \mathrm{Al}) \mathrm{N} / \mathrm{Nb} / \mathrm{TiAl}$ \\
\hline 112 & SS409 & $(\mathrm{Ti}, \mathrm{Al}) \mathrm{N} / \mathrm{Nb} /(\mathrm{TiAl}) \mathrm{N} / \mathrm{Nb} / \mathrm{TiAl}$ \\
\hline
\end{tabular}




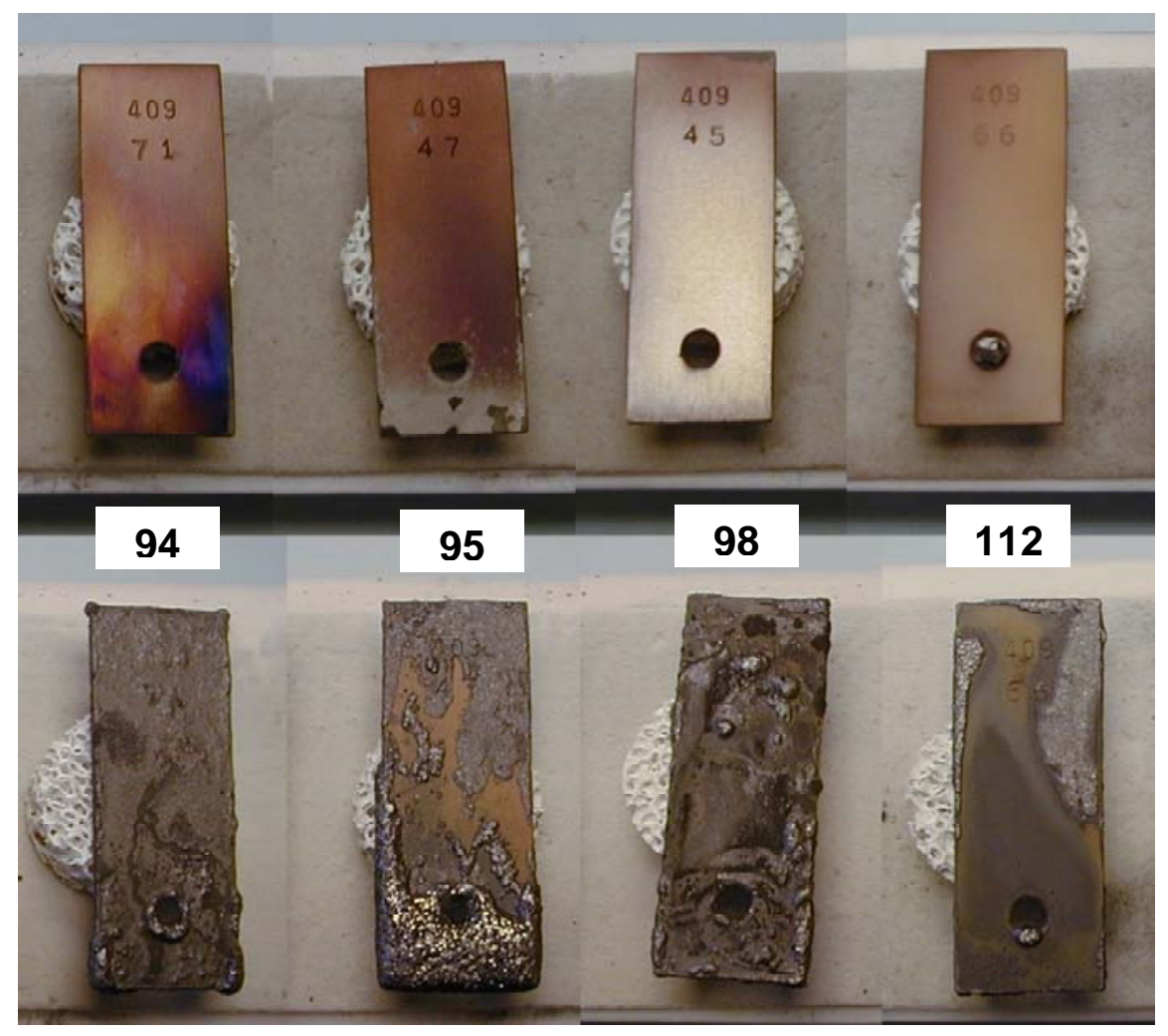

Figure 2. Samples before and after exposure for $300 \mathrm{~h}$ at $900^{\circ} \mathrm{C}$ in simulated gasifier Test 14.

As can be seen in the photographs, samples from Runs 94 and 98 showed general corrosion. Sample 95 was heavily attacked at the area close to the orifice (top zone during the deposition), which accidentally was at the top of the fluidized bed during that Run and therefore was not coated, as seen in the top panel in Figure 2. However, the rest of the sample was mostly free of iron sulfide blisters, typical of sulfide attacked coupons. Sample from Run 112 showed only localized sulfidation attack in two areas, but the rest of the sample resisted the corrosion test. A common feature of the coatings in Runs 95 and 112 is that they have different diffusion barrier interlayers: W interlayer in Run 95 and Nb interlayer in Run 112. The main conclusion of this test is that these interlayers enhance the corrosion resistance of the coupons, probably because they act as a diffusion barrier for $\mathrm{H}_{2} \mathrm{~S}$ to diffuse to the steel and for Fe to diffuse to the surface. Some characterization of samples after exposure to the corrosion test will be presented below. Special attention was paid to sample 112, which showed the highest corrosion resistance.

We performed EDX measurements on the areas where crystals grew during the corrosion test that can be seen by the naked eye (see Figure 2). Results presented in Table 2 show that, as mentioned in previous reports, the crystals are composed mainly of iron sulfides with several 
compositions. Figure 3 shows the X-ray diffraction pattern of crystals grown around the orifice of the sample from Run 95 during the corrosion test. The main peaks match the diffraction pattern of hexagonal pyrrhotite, an iron sulfide with variable stoichiometry. From all these results, it is clear that the corrosion mechanism involves the formation of iron sulfide crystals with several stoichiometries that depend on the iron availability at each area.

Table 3. EDX results, iron sulfide crystals on several samples.

\begin{tabular}{|c|c|cc|c|}
\hline Run & Coupon area & at\% Fe & at\% S & at\% Cr \\
\hline 94 & All areas & 83 & 17 & - \\
\hline \multirow{2}{*}{95} & Crystals around orifice & 58 & 42 & - \\
& Crystals in other zones & 70 & 30 & - \\
\hline \multirow{2}{*}{98} & Crystals, right zone in the photo & 39 & 53 & 8 \\
\hline \multirow{2}{*}{112} & Crystals, top right in the photo & 75 & 25 & - \\
\hline
\end{tabular}

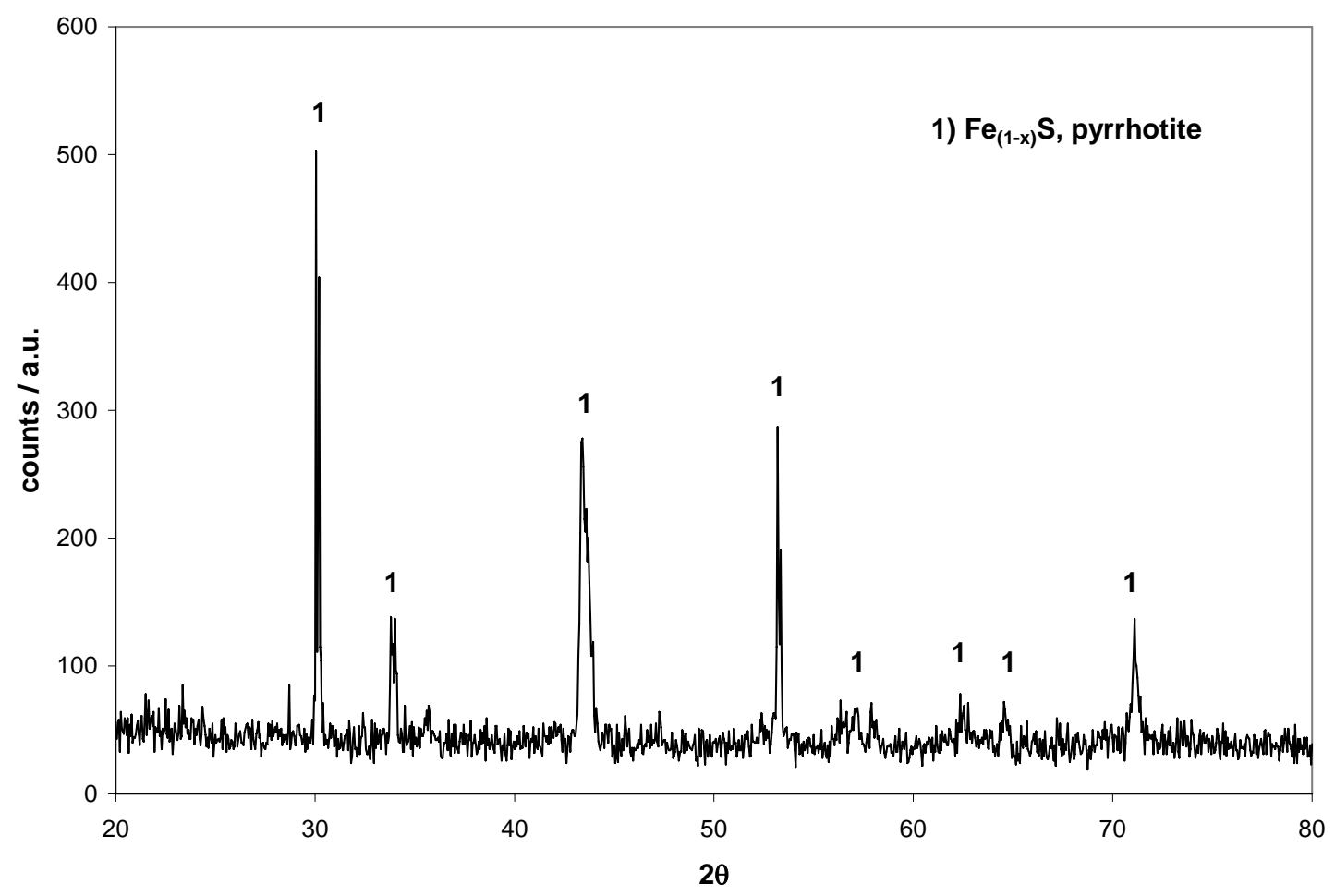

Figure 3. X-ray diffraction pattern of the crystals that grew around the orifice of the sample from Run 95 during exposure to simulated coal gas at $900^{\circ} \mathrm{C}$ for $300 \mathrm{~h}$. 
To gain a better understanding of the protection mechanism provided by the coatings in Runs 95 and 112, we examined the areas that exhibited resistance. Figure 4 shows micrographs at two different magnifications of the zone in coupon from Run 112 that survived the corrosion test. Both the reddish areas and the gray areas observed in Figure 2 show the same morphology: dense crystals are observed covering the surface. The surface composition on that areas found by means of EDX analyses was 77-87 at\% Ti, 6-14 at\% Cr, 4-8 at\% Fe and 0-3 at\% $\mathrm{Al}$ (note that $\mathrm{O}$ was not considered for quantification). The reddish area had 3 at\% $\mathrm{Al}$, whereas we did not find $\mathrm{Al}$ in the gray area. As observed in the EDX spectrum presented in Figure 5, sulfur was not detected in any of these two zones, thus showing that the coatings provided good protection against sulfidation.

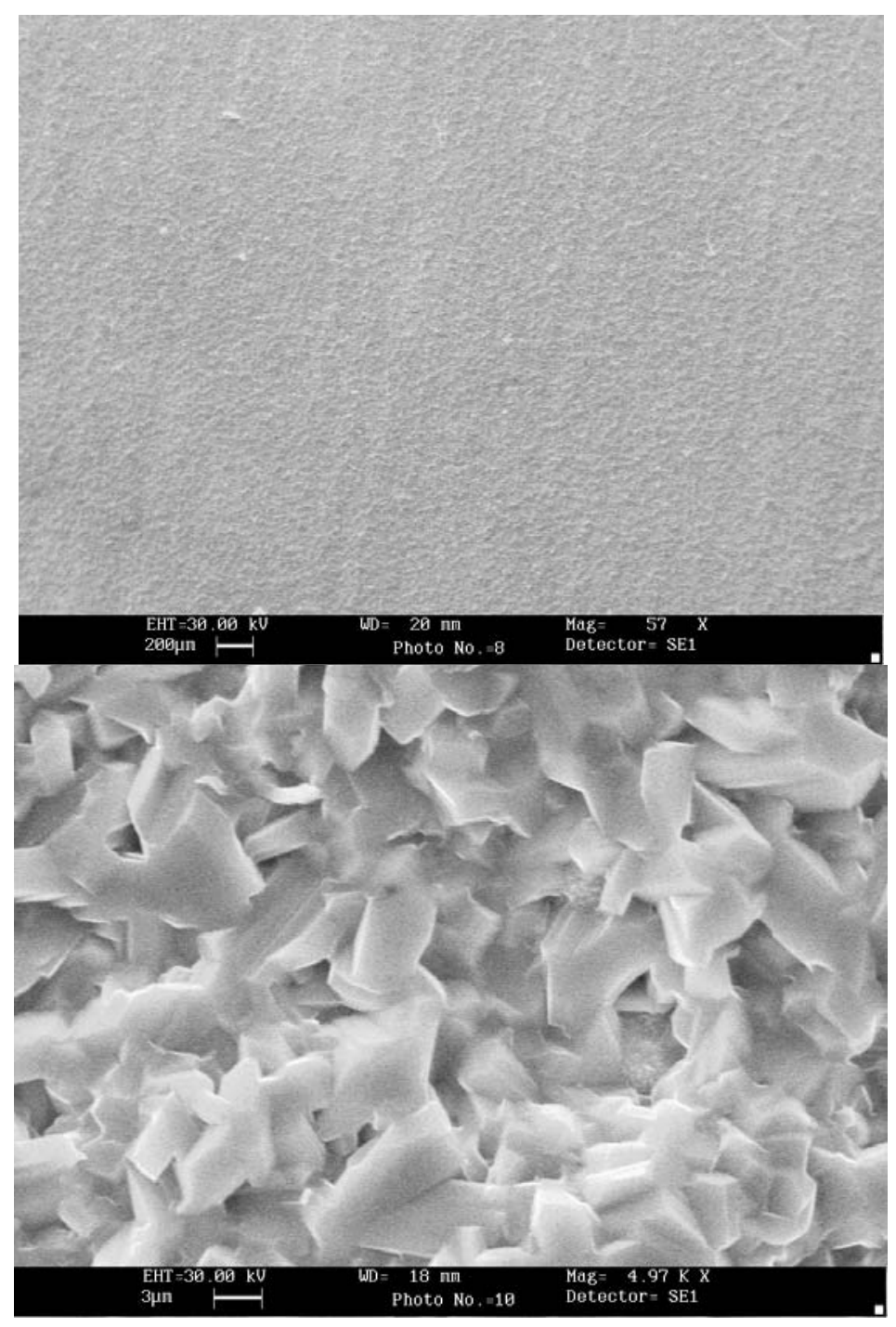

Figure 4. SEM top views at different magnifications of the zone that survived the corrosion test (scale bars are $200 \mu \mathrm{m}$ in the top micrograph and $3 \mu \mathrm{m}$ in the bottom micrograph). 


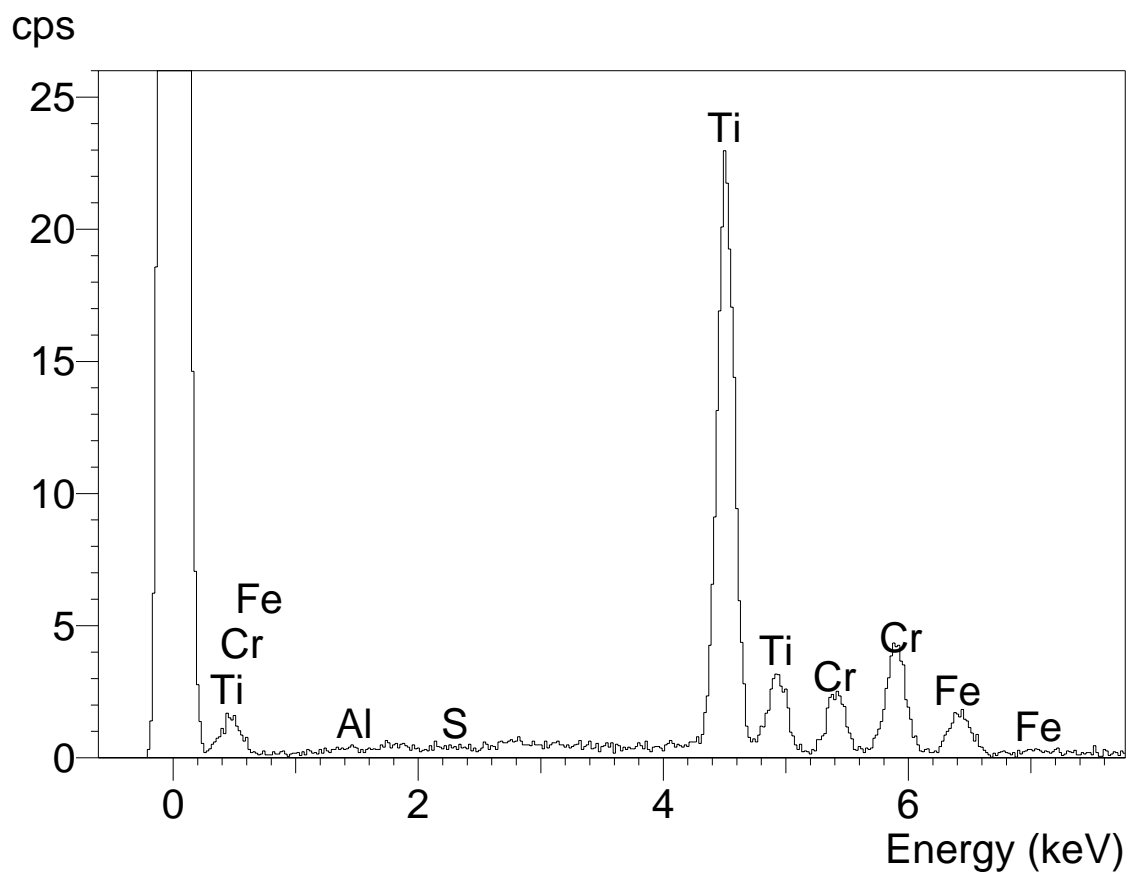

Figure 5. EDX spectrum acquired in the zone showed in Figure 4 (left-hand micrograph).

We performed some XRD measurements in order to determine the phases present in the coating after exposure to the coal gas. Figure 6 shows the diffraction pattern of an unattacked part of the coupon from Run 112 after exposure to the simulated coal gas at high temperature. The only observed peak corresponding to steel has very low intensity, indicating that the overlaying coating is thick. The main peaks in the spectrum correspond to rutile, a phase of titanium dioxide $\left(\mathrm{TiO}_{2}\right)$. This result shows that the oxygen activity as a result of the water vapor in the system is high enough to fully oxidize TiN. The resulting oxide coating must be dense, free of cracks, and therefore protective against sulfidation. Two chromium oxide phases are observed in the XRD spectrum: $\mathrm{CrO}$ and $\mathrm{Cr}_{2} \mathrm{O}_{3}$. It is well known that chromium oxide scales provide corrosion protection in many environments, so the formation of these phases provide an added protection to the steel substrate. 


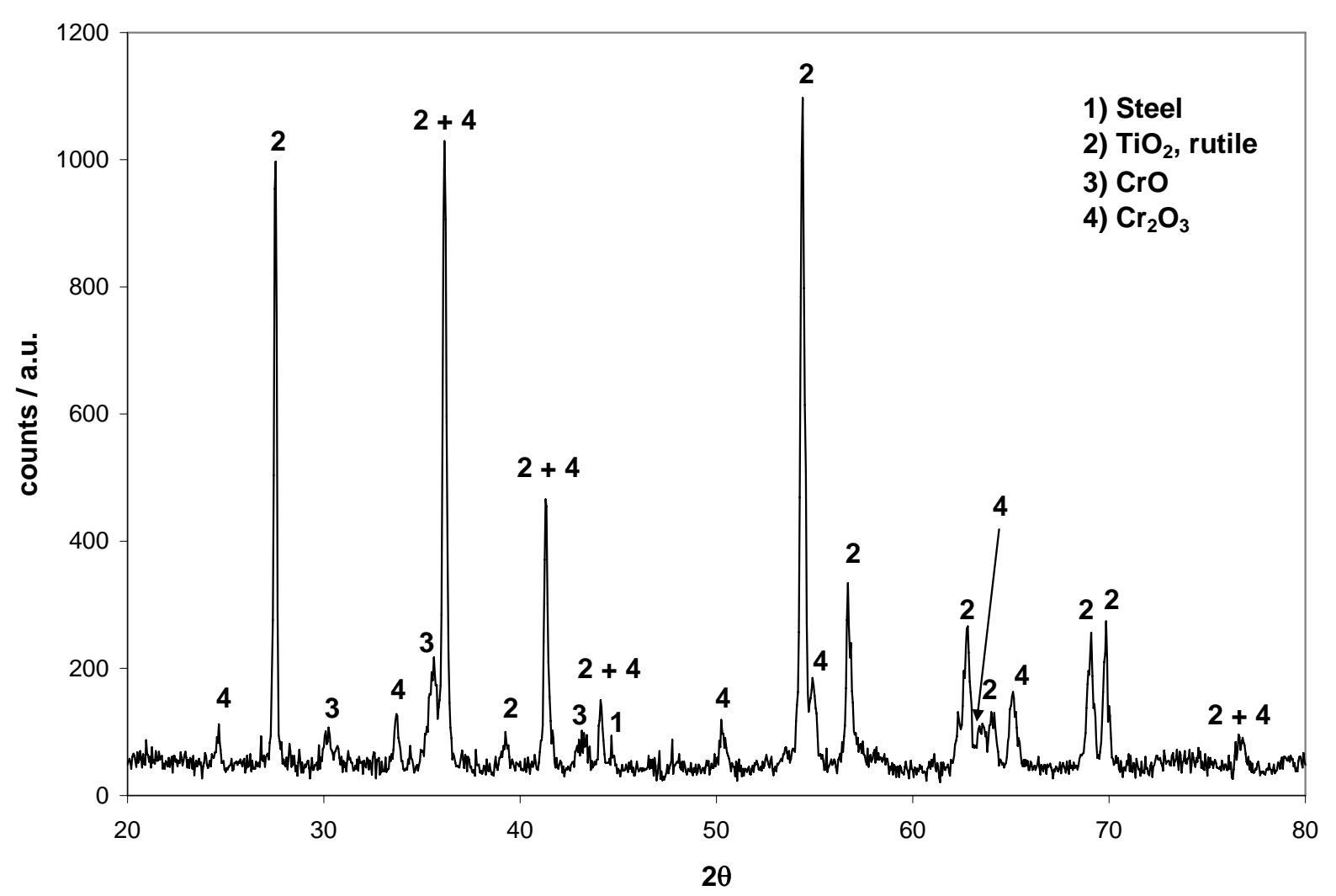

Figure 6. X-ray diffraction pattern of the zone from coupon 112 that survived sulfidation during exposure to simulated coal gas at $900^{\circ} \mathrm{C}$ for $300 \mathrm{~h}$.

In order to study the coating morphology after exposure to coal simulated gas at high temperature, the coupon was intentionally fractured. A cross-sectional SEM view is presented in Figure 7. EDX measurements showed that the zone labeled as 1 in the micrograph corresponds to the titanium dioxide scale observed also in top SEM views (Figure 4) and detected by means of XRD measurements (Figure 6). Interestingly, the zone labeled as 2 had a high $\mathrm{Cr}$ content (77.8 at\%), some $\mathrm{Ti}(13.0$ at\%) and Fe (9.2 at\%). It is probably in this area that the mixture of chromium oxides detected by XRD were formed. The zone labeled as 3 is the base 409 stainless steel. As a conclusion, the characterization of the areas that survived the corrosion test shows that during exposure to simulated coal gas at $900^{\circ} \mathrm{C}$ protective titanium and chromium oxide scales were formed. 


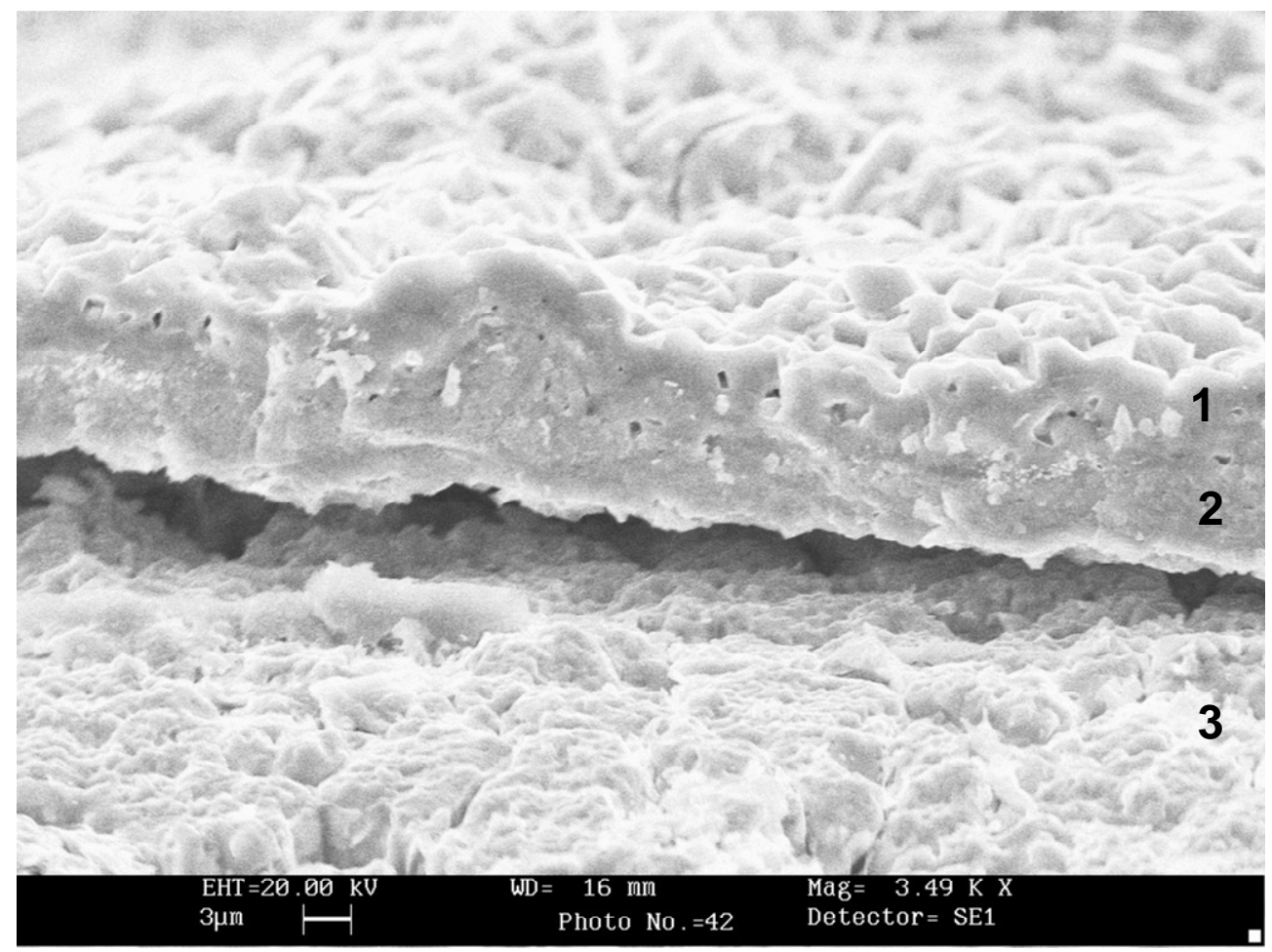

Figure 7. Cross-section micrograph of the exposed coupon from Run 112 after fracturing.

\section{ANALYSIS OF COUPONS EXPOSED TO SIMULATED COAL GAS}

The results discussed in the previous section show that coatings containing a combination of several ceramic/metal layers can protect 409 steel coupons during exposure to simulated coal gas at $900^{\circ} \mathrm{C}$. We decided to study the effect of increasing the number of individual layers and deposited coatings containing 4 ceramic layers and 4 metal interlayers. We carried out several deposition experiments to test the performance of $\mathrm{Nb}, \mathrm{Ta}, \mathrm{Zr}$ and $\mathrm{W}$ as metal interlayers (see Table 4).

Characterization of similar coatings with less layers have been discussed in previous reports. Thus, in this report we will only include a brief description on morphology and adhesion of coatings from Runs 119, 120, 121 and 122. Coatings deposited in Runs 119 and 120 (with $\mathrm{Nb}$ and Ta interlayers) showed good adhesion. Cross-sectional views of a coupon from Run 120 after mounting and polishing (Figure 8) and after fracturing it (Figure 9) revealed that the desired 
layered structure was achieved. As observed in Figure 8, the coating was conformal and showed good adhesion to the substrate (note that the sample was mounted under pressure). Figure 9 shows that the individual layers are dense and have a fine grained structure.

Table 4. Multilayer coatings deposited.

\begin{tabular}{|c|c|c|}
\hline Run & Material & Coating \\
\hline 119 & SS409 & $4 \times[(\mathrm{Ti}, \mathrm{Al}) \mathrm{N} / \mathrm{Nb}] / \mathrm{TiAl}$ \\
\hline 120 & $\mathrm{SS} 409$ & $4 \times[(\mathrm{Ti}, \mathrm{Al}) \mathrm{N} / \mathrm{Ta}] / \mathrm{TiAl}$ \\
\hline 121 & $\mathrm{SS} 409$ & $4 \times[(\mathrm{Ti}, \mathrm{Al}) \mathrm{N} / \mathrm{Zr}] / \mathrm{TiAl}$ \\
\hline 122 & $\mathrm{SS} 409$ & $4 \times[(\mathrm{Ti}, \mathrm{Al}) \mathrm{N} / \mathrm{W}] / \mathrm{TiAl}$ \\
\hline
\end{tabular}

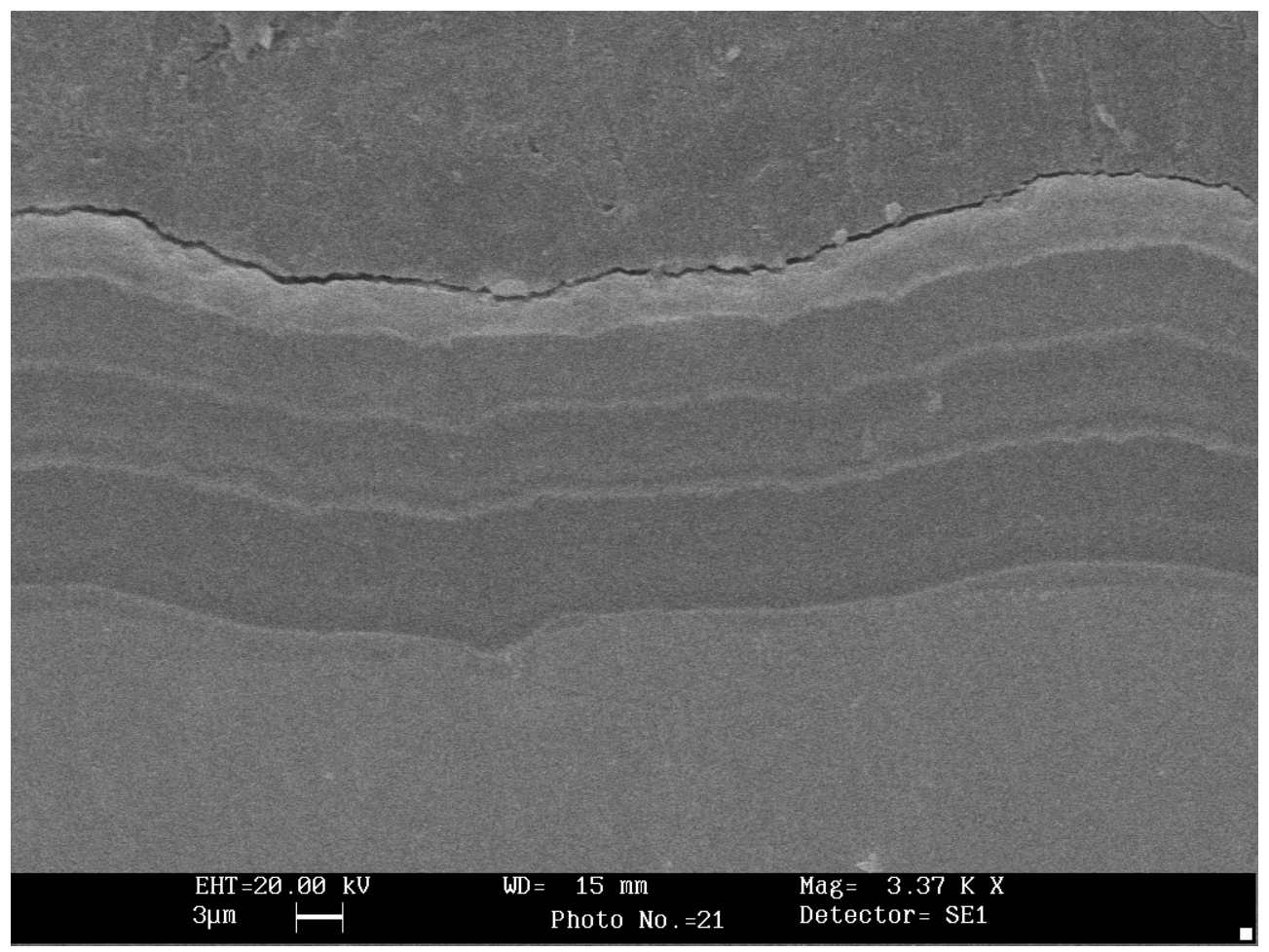

Figure 8. SEM cross-section of a sample from Run 120 showing the substrate (bottom), the multilayer coating and the mounting polymer (top). 


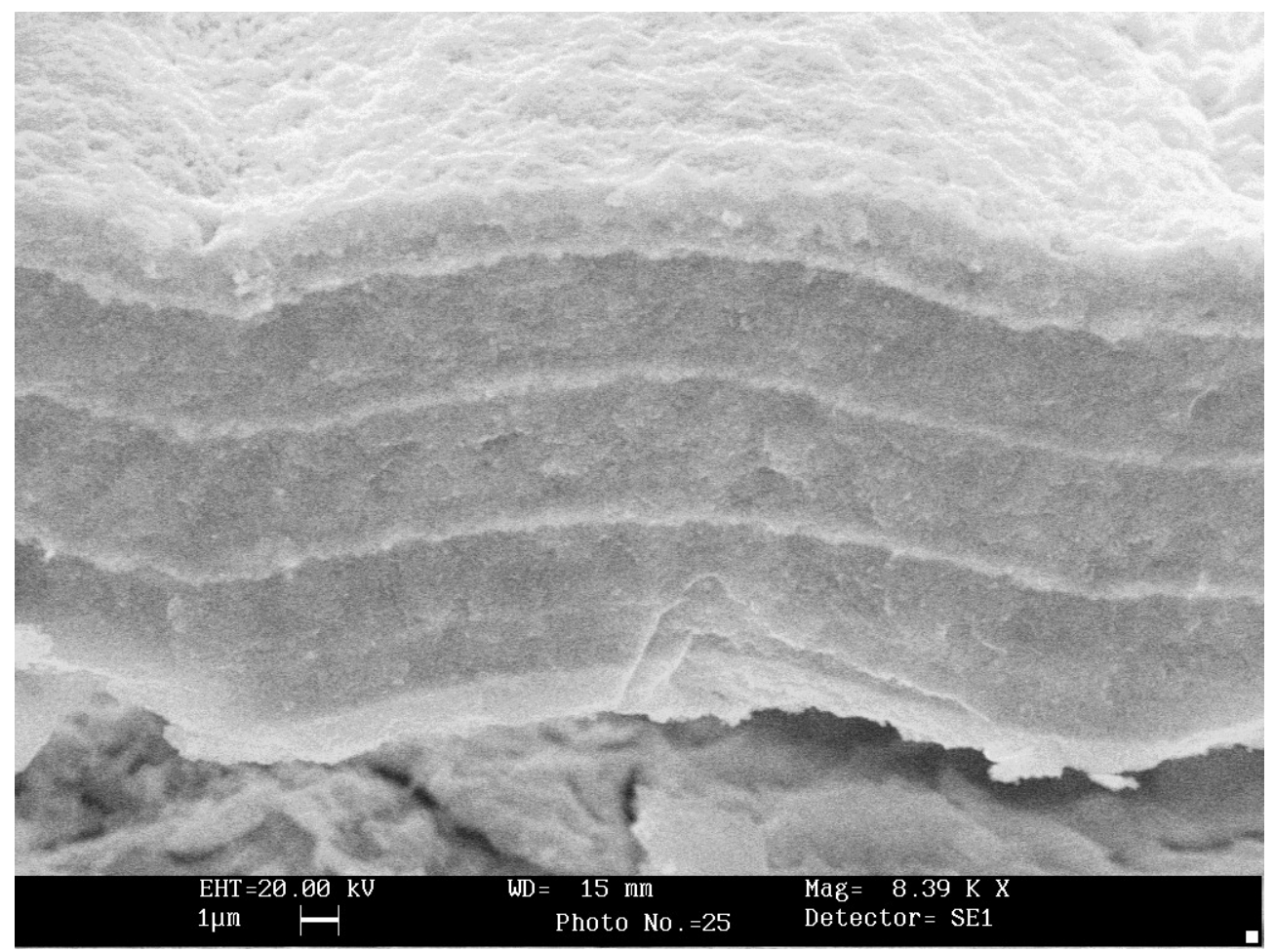

Figure 9. SEM cross-section of the fractured sample showing a closer view of the coating.

In a sample from Run 121 we did not observe the multilayer structure, but some Zr was detected by cross-sectional EDX measurements. Further characterization is needed to understand the processes that took place during deposition. On the other hand, sample from Run 122 has poor adhesion over extended areas. XRD analysis revealed that the coatings contain a mixture of tungsten and tungsten nitride $\left(\mathrm{W}_{2} \mathrm{~N}\right)$. In a similar coating deposited in a hot wall reactor we did not observe any $\mathrm{W}_{2} \mathrm{~N}$, so the delaminating could be solved by lowering the substrate temperature during $\mathrm{W}$ deposition.

\section{ANALYSES OF MULTILAYER-COATED COUPONS AFTER EXPOSURE TO COAL GAS}

Coupons coated with the multilayers described in the previous section were exposed to simulated coal gas at $900^{\circ} \mathrm{C}$. Figure 10 shows a picture of the samples before and after the corrosion test. As can be seen, the coupon from Run 119 (Nb interlayers) showed good sulfidation resistance under the tested conditions. The weight change that we measured was only of $1.2 \%$ (typical weight gains in similar coupons were in the range $5-10 \%$ if they showed partial corrosion resistance, and above $10 \%$ if they were severely attacked). As observed in the picture, minor 
corrosion was observed only in two zones at the edge of the coupon, due to normal vertical inhomogeneities in the laboratory reactor. Examination of the corroded areas in other samples revealed that the sulfide scales formed had the same composition and morphology found in previous corrosion tests.

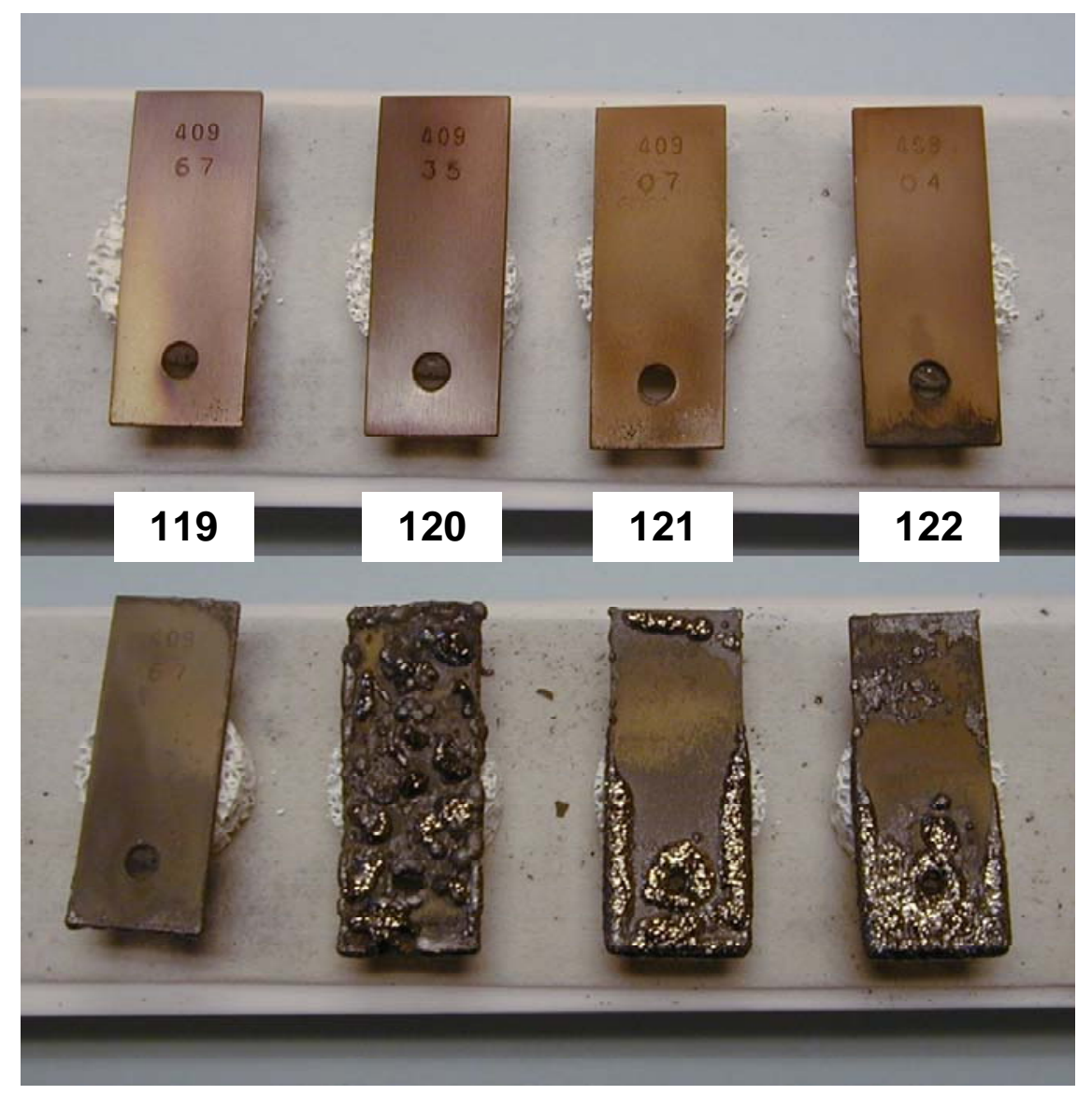

Figure 10. Samples before and after exposure for $300 \mathrm{~h}$ at $900^{\circ} \mathrm{C}$ in simulated gasifier Test 15 .

A top SEM observation of the coupon from Run 119 after exposure to simulated coal gas (Figure 11) showed that it has the same surface morphology as found in coupon areas that survived during exposure in the previous corrosion test, namely, a homogeneous microcrystalline coating. EDX analyses in several areas revealed the following surface composition: 1-2 at\% $\mathrm{Al}$, 92-95 at\% Ti, 2-4 at\% Cr, 0-2 at\% Fe and 1 at\% Nb. We did not detect any S by means of EDX measurements, indicating that no sample sulfidation occurred. 


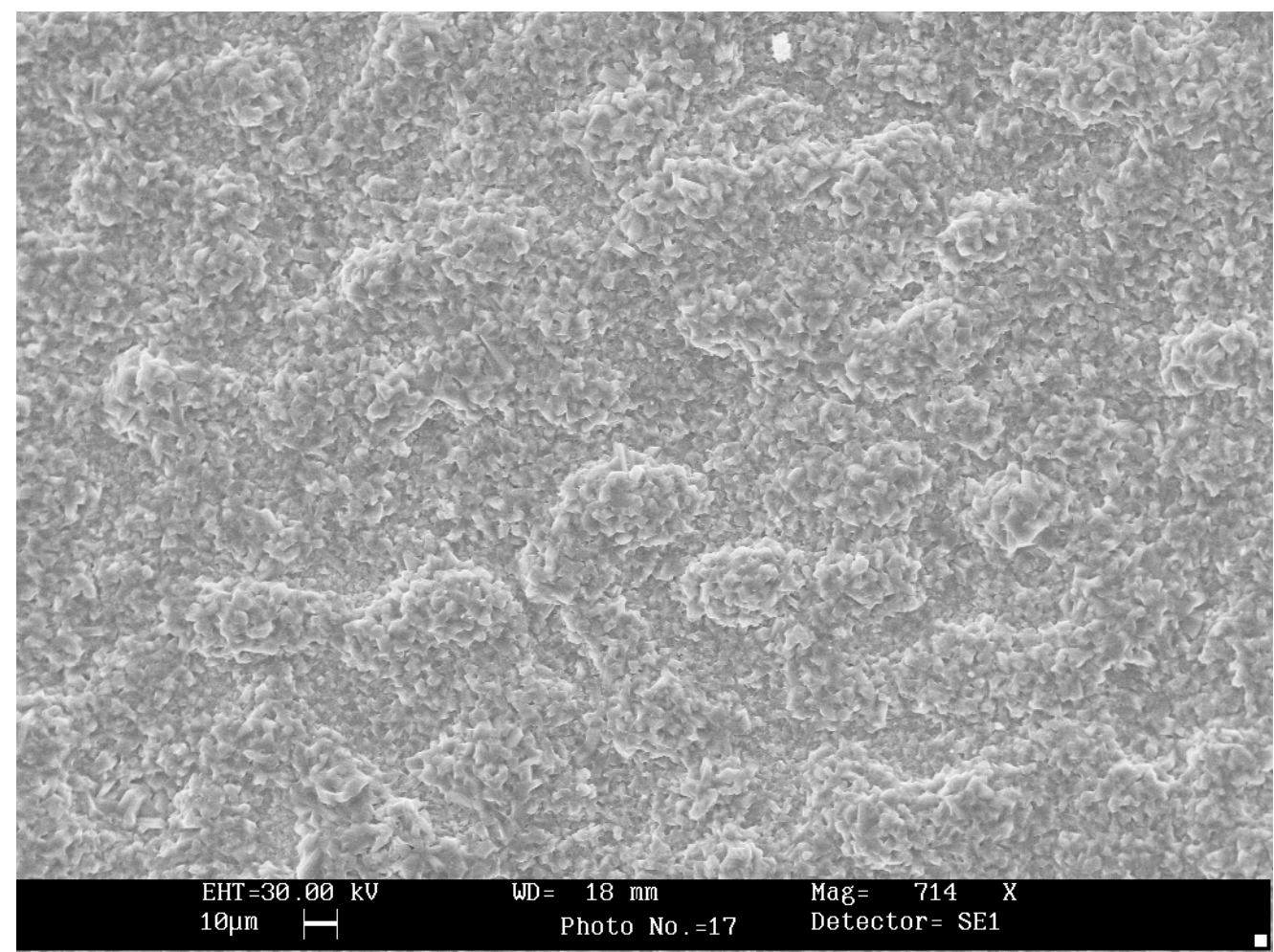

Figure 11. SEM top view of the coupon from Run 119 after exposure to simulated coal gas at $900^{\circ} \mathrm{C}$ for $300 \mathrm{~h}$ (scale is $10 \mu \mathrm{m})$

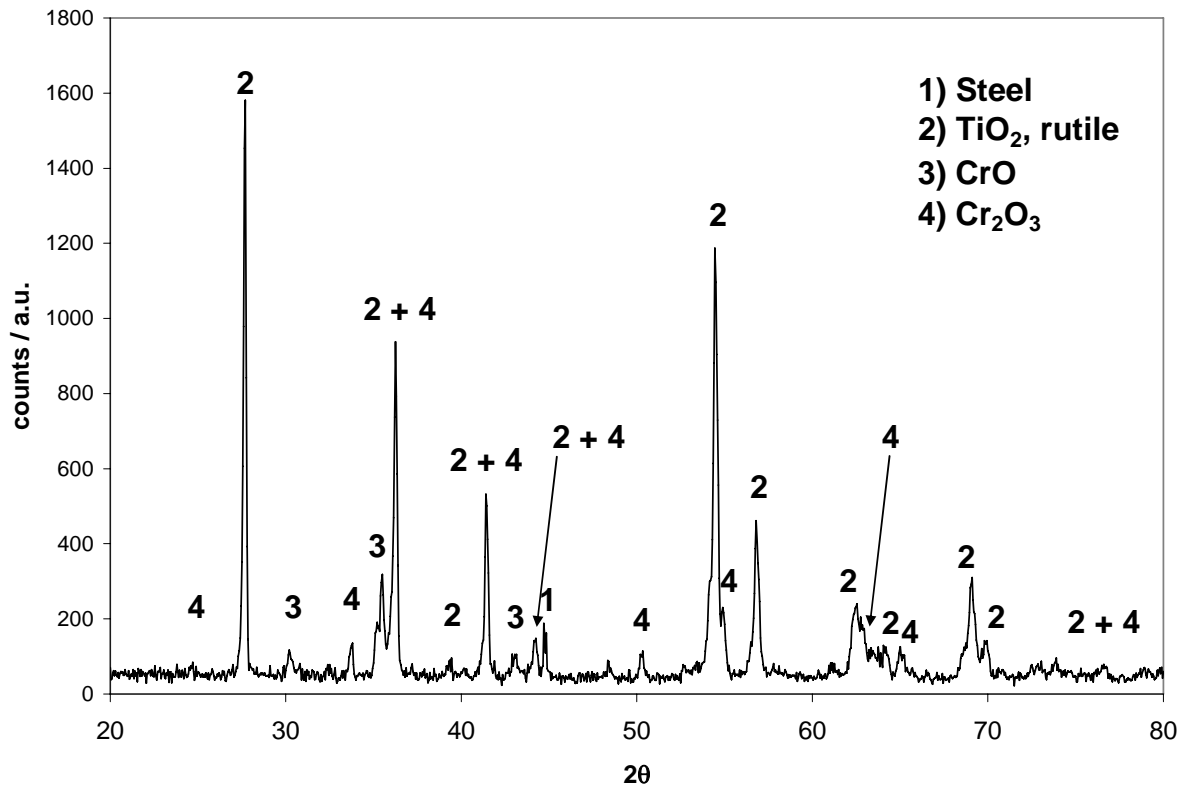

Figure 12. X-ray diffraction pattern, coupon from Run 119 after exposure to simulated coal gas at $900^{\circ} \mathrm{C}$ for $300 \mathrm{~h}$. 
Since O was not included in the EDX quantification analyses, XRD measurements (Figure 12) were carried out to confirm that the crystals at the surface were $\mathrm{TiO}_{2}$, as found in previous experiments. Some low-intensity peaks corresponding to chromium oxides were also be observed in the spectrum indicating that chromium oxide scales were formed between the substrate and the Ti-based coating. This chromium oxide layer provides probably an extra protection to the steel substrate by slowing down the outward diffusion of Fe.

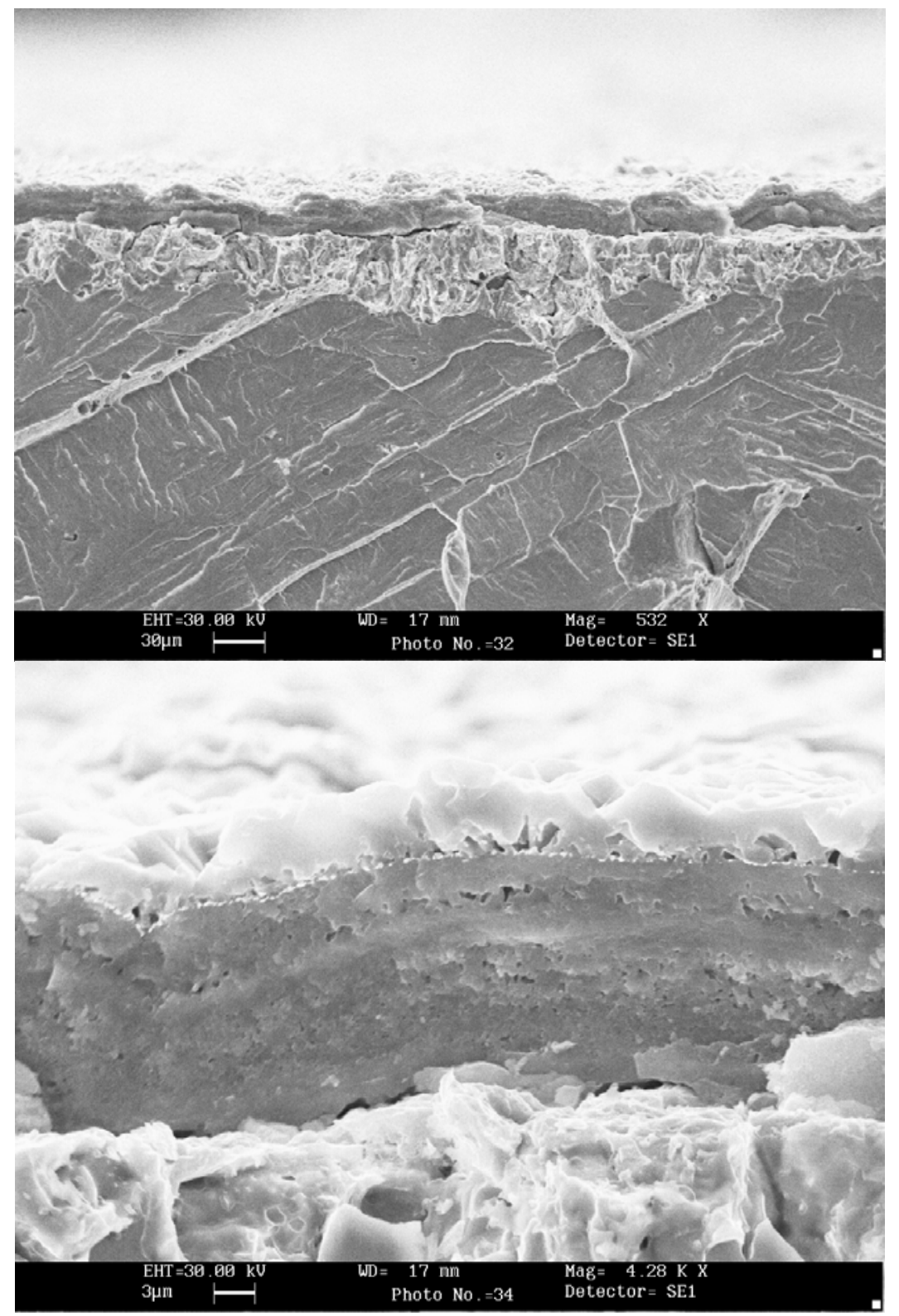

Figure 13. Cross-section micrographs at two different magnifications of the exposed coupon from Run 119 after fracturing (scale bars are $30 \mu \mathrm{m}$ in top micrograph and $3 \mu \mathrm{m}$ in bottom micrograph). 
Figure 13 is the SEM cross-sectional views at two magnifications of the exposed coupon from Run 119 after intentionally fracturing it. The titanium dioxide $\left(\mathrm{TiO}_{2}\right)$ crystals that form the external coating layer are clearly seen. Although, as a result of elemental diffusion and oxide formation there is some porosity, after exposure to the corrosion test the coating is still relatively dense. The results of a line EDX analysis carried out across the coating are presented in Figure 14. From left to right in each plot, the Ti-based coating and some $\mathrm{Nb}$ - and $\mathrm{Cr}$-rich layers are clearly seen. In the Fe plot it is clearly seen that outward diffusion of this element was blocked by the coating. Since Fe diffusion is known to be the key process leading to corrosion of steels by sulfidation in the tested environment, this result shows that a multilayer coating formed by combination of Ti-based nitride films with $\mathrm{Nb}$ interlayers is a good candidate for protecting parts of coal gasification plants.

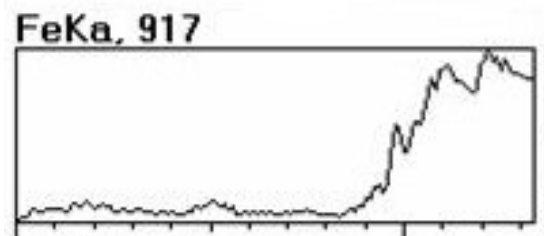

NbLa1, 103
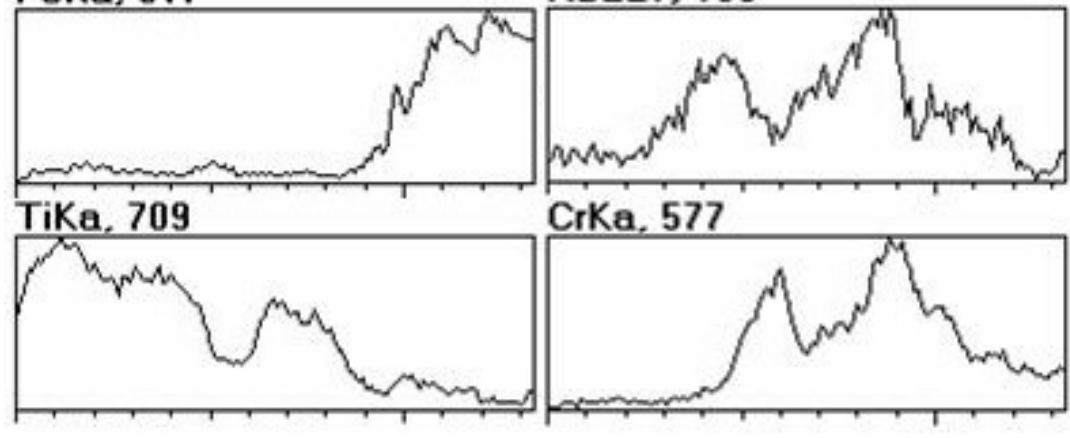

CrKa. 577

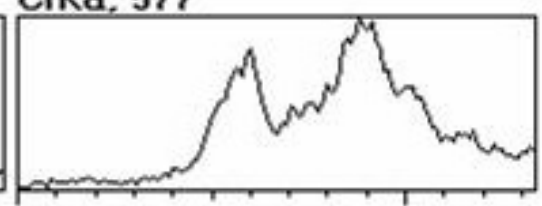

Figure 14. Elemental EDX line analysis across the coating shown in the bottom micrograph in Figure 13 (Origin in $\mathrm{x}$-axis corresponds to coating surface).

\section{CONCLUSIONS AND FUTURE WORK}

- Coatings composed of titanium and silicon nitrides in combination with a $\mathrm{Nb}$ diffusion barrier provide protection against sulfidation in porous samples in a simulated coal gas at $370^{\circ} \mathrm{C}$ for $300 \mathrm{~h}$.

- Coatings composed of titanium and aluminum nitrides in combination with several $\mathrm{Nb}$ interlayers provide protection against sulfidation in porous samples in a simulated coal gas at $900^{\circ} \mathrm{C}$ for $300 \mathrm{~h}$.

- Protection of coated coupons at $900^{\circ} \mathrm{C}$ is achieved by a double effect: the formation of a dense $\mathrm{TiO}_{2}$ film that hinders $\mathrm{H}_{2} \mathrm{~S}$ to diffuse to the steel substrate, and the reduction in $\mathrm{Fe}$ outward diffusion provided by the $\mathrm{Nb}$ interlayers. 
In light of these promising results, we believe that it would be of interest to explore the coating based in TiAlN/Nb multilayers to determine the effect in corrosion resistance of parameters such as number of layers and thickness of individual layer in long-term experiments. 